\title{
ANALISIS DAUR HIDUP PRODUK (PRODUCT LIFE CYCLE) BIHUN TAPIOKA DI PROVINSI LAMPUNG
}

\author{
(Analysis of Product Life Cycle of Tapioca Vermicelli In Lampung)
}

Rizky Fitrianingsih Dalimunthe, Wuryaningsih Dwi Sayekti, Ani Suryani

Jurusan Agribisnis, Fakultas Pertanian, Universitas Lampung, Jl. Prof. Dr. Soemantri Brodjonegoro No. 1

Bandar Lampung 35145, e-mail: wuryaningsih.dwisayekti@fp.unila.ac.id

\begin{abstract}
This research aims to analyze the position of tapioca vermicelli production on the product life cycle (PLC), to know the manufacturer's perception of the development of tapioca vermicelli business, and correlation between the perception and the PLC. This research used a case study method at tapioca vermicelli industries, namelySinar Jaya (SJ), SinarHarapan (SH), Monas Lancar (ML), Bintang Obor (BO), and Moro Seneng (MS). Respondents are the owners of the agroindustries. Data were analyzed using a descriptive statistical analysis and qualitative descriptive. The results showed that the positions of tapioca vermicelli product in terms of the product life cycle in SJ, ML, and MSare in the Growth Stage, while those of SH and $B O$ are at the Maturity Stage. Business development is perceived as important by producers, but it is difficult to do. There is no correlation between perceptions of the development of the business and the product life cycle.
\end{abstract}

Keywords: perception, PLC, tapioca vermicelli.

\section{PENDAHULUAN}

Beras merupakan pangan pokok bagi sebagian besar masyarakat Indonesia.Ketergantungan pada beras yang tingi, sangat tidak menguntungkan bagi kelangsungan ketahanan pangan nasional karena jumlah penduduk Indonesia sangat besar dengan cakupan geografis yang luas dan tersebar. Kebutuhan beras yang tinggi membuat Indonesia melakukan impor beras dari negara lain. Pemerintah dalam mewujudkan ketahanan pangan nasional perlu melakukan program diversifikasi pangan sumber karbohidrat selain beras.

Diversifikasi pangan merupakan upaya untuk menganekaragamkan pola konsumsi pangan masyarakat dalam rangka meningkatkan mutu gizi makanan yang dikonsumsi yang pada akhirnya akan meningkatkan status gizi penduduk (Almatsier 2001). Pengganti beras tersebut harus bersumber dari komoditas lokal bernutrisi dan aman untuk dikonsumsi.Salahsatu bahan makanan yang dapat menggantikan beras adalah kelompok umbi-umbian yaitu ubi kayu (Kementerian Pertanian 2016).

Ubi kayu merupakan salah satu bahan makanan pengganti beras yang cukup penting peranannya dalam menopang ketahanan pangan suatu wilayah. Provinsi Lampung sebagai sentra penghasil ubi kayu dengan rata-rata produksi mencapai 7,74 juta ton di urutan pertama nasional (BPS Provinsi Lampung 2017). Banyaknya ubi kayu yang ada di Provinsi Lampung memunculkan berbagai macam jenis agroindustri yang berbahan dasar ubi kayu.

Agroindustri adalah salah satu konsep pendekatan pembangunan pertanian yang merupakan bagian dari 6 (enam) subsistem agribisnis yang disepakati selama ini yaitu subsistem penyediaan sarana produksi dan peralatan, usahatani, pengolahan hasil pertanian, sarana, pembiayaan dan pemasaran (Soekartawi 2000).Agroindustri ubi kayu berperan penting dalam mewujudkan program diversifikasi pangan.Jumlah agroindustri (pengolahan hasil pertanian) ubi kayu di Provinsi Lampung sebanyak 123 unit (Dinas Perindustrian Provinsi Lampung 2017).

Ubi kayu dapat dijadikan berbagai macam olahan makanan, salah satu olahan ubi kayu adalah bihun tapioka.Bihun tapioka merupakan bihun atau mi yang terbuat dari bahan dasar ubi kayu.Olahan ubi kayu banyak dikenal oleh masyarakat, sehingga menjadikan olahan tersebut sebagai pilihan keberagaman pangan yang belum terlihat keberhasilannya.Salah satu daerah di Provinsi Lampung yang terdapat produsen pengolahan tepung tapioka menjadi bihun tapioka adalah Kota Metro dan Kabupaten Lampung Timur.Kota Metro dan Kabupaten Lampung Timur merupakan daerah di Provinsi Lampung yang terdapat agroindustri ubi kayu yang diolah menjadi bihun tapioka. 
Kota Metro terdapat dua kecamatan yang mempunyai produsen bihun tapioka, yaitu Kecamatan Metro Timur dan Kecamatan Metro Utara.Kabupaten Lampung Timur yang terdapat produsen bihun tapioka yaitu daerah di Kecamatan Pekalongan.

Menurut hasil penelitian Sayekti, Prasmatiwi, dan Adawiyah (2007) rata-rata jumlah konsumsi bihun tapioka di Kota Metro oleh konsumen rumah tangga adalah sebanyak 733,87 gram per rumah tangga per bulan dengan frekuensi pembelian 1-2 kali per bulan. Berdasarkan hasil penelitian Vidyaningrum, Sayekti, dan Adawiyah (2016) rata-rata konsumsi bihun tapioka oleh rumah tangga di Kecamatan Purbolinggo Kabupaten Lampung Timur yaitu sebanyak 1.300 gram per rumah tangga per bulan dengan frekuensi pembelian 2 kali per bulan. Data tersebut menunjukkan bahwa rata-rata konsumsi bihun tapioka mengalami peningkatan walaupun peningkatan konsumsi tersebut hanya terdapat pada daerah yang memiliki agroindustri bihun tapioka.

Hasil penelitian Sayekti et al. (2007) lebih lanjut menyatakan produsen bihun tapioka di Kota Metro masih pasif dalam melakukan strategi pemasaran.Produsen bihun tapioka hanya memperhatikan pada masalah produksi sedangkan aspek pasar belum diperhatikan.Jumlah produksi bihun tapioka tergantung dari permintaan distributor sehingga pemasaran bihun tapioka lebih banyak dilakukan oleh distributor.Hal tersebut didukung oleh hasil penelitian Bazai, Sayekti dan Lestari (2017) yang menyatakan pada proses pendistribusian bihun tapioka di Kota Metro kepada konsumen hanya dilakukan oleh distributor, sedangkan produsen bihun tapioka hanya menjual bihun tapioka di pabrik saja.

Permasalahan pada agroindustri bihun tapioka adalah produsen bihun tapioka yang tidak melakukan pengembangan ide, inovasi dan kreativitas pada produk bihun tapioka yang diproduksinya.Selain itu, produsen kurang mampu untuk membuat suatu strategi pemasaran yang sesuai untuk produk bihun tapioka.Oleh karena itu, bihun tapioka hanya dikenal oleh masyarakat di daerah-daerah tertentu saja.Produsen bihun tapioka perlu memperhatikan langkah-langkah strategi pemasaran sesuai tahapan produk bihun tapioka serta pendapat mengenai pengembangan usahanya agar tujuan agroindustri tercapai.Pencapaian laba meningkat, serta mempertahankan kelangsungan hidup agroindustri bihun tapioka, sehingga volume penjualan produk bihun tapioka dapat berkembang ke luar daerah Kota Metro dan Kabupaten Lampung Timur.

Kenyataan bahwa produsen bihun tapioka yang pasif dalam pemasaran memunculkan pertanyaan bagaimana persepsi produsen bihun tapioka dalam pengembangan usahanya.Selanjutnya perlu juga diketahui hubungan antara persepsi dalam pengembangan produk bihun tapioka dengan tahapan daur hidup produk.Kotler (2000) menyatakan bahwa setiap tahap siklus hidup produk (Product Life Cycle) memerlukan strategi pemasaran yang berbeda.Pada daur hidup produk terdapat 4 (empat) tahapan yaitu tahapan pengenalan, tahapan pengembangan, tahapan kedewasaan dan tahapan penurunan.Oleh karena itu, perlu dilakukan penelitian mengenai "Analisis Daur Hidup Produk Bihun Tapioka di Provinsi Lampung".

Tujuan dari penelitian ini adalah mengetahui daur hidup produk (Product Life Cycle) bihun tapiokadi Provinsi Lampung dan mengetahui persepsi produsen terhadap pengembangan usaha bihun tapioka dan keterkaitan persepsi produsen terhadap pengembangan usaha dengan (Product Life Cycle).

\section{METODE PENELITIAN}

Metode yang digunakan dalam penelitian ini adalah sensus.Pemilihan lokasi ditentukan secara sengaja (purposive) dengan pertimbangan bahwa hanya di Kota Metro dan Kabupaten Lampung Timur terdapat usaha pengolahan (agroindustri) ubi kayu menjadi bihun tapioka. Provinsi lampung hanya terdapat lima agroindustri bihun tapioka yang masih aktifberproduksi. Pada penelitian ini kelima agroindustri tersebut dijadikan objek penelitian.

Data yang dikumpulkan dalam penelitian ini berupa data primer dan sekunder.Data primer mencakup data terkait dengan posisi produk bihun tapioka dalam daur hidup produk dan persepsi produsen terhadap pengembangan usaha.Data primer tersebut diperoleh dengan wawancara langsung. Data sekunder mencakup antara lain data jumlah agroindustri ubi kayu di Provinsi Lampung bersumber dari Dinas Perindustrian Provinsi Lampung. Waktu pengumpulan data penelitiandilakukan pada bulan Februari sampai April 2018.

Tujuan pertamayaitu analisis daur hidup produk dianalisis dengan metodePolli and Cook. 
Langkah-langkah perhitungan menurut Polli and Cook (1996) dalam Maulani, Dwiastuti, dan Andriani (2017) yaitu sebagai berikut:

(1) Mengurutkan besarnya penjualan pertahun.

(2) Menghitung persentase perubahan setiap tahun kemudian hitung total dari persentase penjualan yang merupakan nilai harapan (expected value) untuk $\chi$ (persentase perubahan penjualan pertahun) digunakan perhitungan sebagai berikut :

Penjualan tahun ini-Penjualan tahun lalu Penjualan tahun lalu

(3) Menghitung total rata-rata persentase perubahan penjualan, sehingga diperoleh besarnya nilai $\mu$. Kemudian nilai $\chi$ dikurangkan dengan $\mu$ setiap periode pengamatan.

(4) Perhitungan pada langkah ke-3 dikuadratkan dan dihitung nilai totalnya setelah itu dapat dilihat standar deviasinya $\left(\sigma^{2}\right)$.

(5) Mencari nilai $\mu+0,5 \sigma$ sehingga didapatkan untuk $\mathrm{z}$ dan $\mu+0,5 \sigma$ untuk memperoleh $\mathrm{y}$.

Hasil perhitungan yang diperoleh berdasarkan rumus di atas, maka dapat ditemukan tahap daur hidup produk berdasarkan batasan-batasan sebagai berikut :

(1) Tahap pertumbuhan ditandai apabila jumlah nilai persentase perubahan penjualan lebih besar dari $\mu+0,5 \sigma$

(2) Tahap kedewasaan ditandai apabila jumlah nilai persentase perubahan penjualan diantara $\mu-0,5 \sigma$ atau $\mu+0,5 \sigma$

(3) Tahap penurunan ditandai apabila jumlah nilai persentase perubahan penjualan kurang dari $\mu$ $-0,5 \sigma$

Analisis kedua untuk mengetahui persepsi produsen terhadap pengembangan usaha agroindustri bihun tapioka dan keterkaitan persepsi produsen terhadap pengembangan usaha agroindustri dengan Product Life Cycle yangdianalisis dengan statistik deskriptif.Pengukuran persepsi menggunakan skala ordinal melalui Likert's Summated Rating Scale (LSRS) dimana setiap pilihan jawaban diberi skor.Lima indikator yang digunakan yaitu pentingnya pengembangan usaha, jumlah produk, pengembangan pasar, omzet usaha, dan kelangsungan usaha.Hasil pengukuran klasifikasi penilaian dapat dilihat pada Tabel 1 .
Tabel 1.Klasifikasi penilaian persepsi

\begin{tabular}{cccc}
\hline No. & Kategori & Skala & Skor \\
\hline 1 & Sangat Rendah (SR) & 1 & $1,00-1,80$ \\
2 & Rendah (R) & 2 & $1,81-2,61$ \\
3 & Sedang ( S) & 3 & $2,62-3,42$ \\
4 & Tinggi (T) & 4 & $3,43-4,23$ \\
5 & Sangat Tinggi (ST) & 5 & $4,24-5,04$ \\
\hline
\end{tabular}

Tabel 1 hasil pengukuran klasifikasi penilaian persepsi dimana dari nilai modus berdasarkan skor jawaban yang telah diberikan. Klasifikasi dalam lima kelas yaitu "sangat tinggi", "tinggi", "sedang", "rendah", dan "sangat rendah".

Interval $=\frac{\text { skor tertinggi }- \text { skor terendah }}{\text { banyak kelas }}$

Tingkat persepsi produsen yang digunakan dapat dibuat dengan pengklasifikasian kelas dengan menggunakan interval 0,8 . Selanjutnya untuk mengetahui keterkaitan persepsi produsen terhadap pengembangan usaha dengan Product Life Cycle yaitu menggunakan tabulasi silang.

\section{HASIL DAN PEMBAHASAN}

\section{Karakteristik Responden Pemilik atau Pengelola Agroindustri dan Konsumen}

Berdasarkan hasil penelitian, diketahui bahwa umur pemilik atau pengelola Agroindustri Bihun Tapioka Sinar Jaya (SJ), Agroindustri Sinar Harapan (SH), Agroindustri Monas Lancar (ML), Agroindustri Bintang Obor (BO), dan Agroindustri Moro Seneng (MS) berkisar di antara 47-58 tahun. Seluruh responden pernah menerima pendidikan formal dengan tingkat pendidikan terendah SD dan tertinggi SMA.Agroindustri bihun tapioka didirikan sudah sejak lama, namun latar belakang pendirian kelima agroindustri terdapat persamaan yaitu merupakan usaha keluarga.

\section{Daur Hidup Produk (Product Life Cycle) Bihun Tapioka di Provinsi Lampung}

Daur hidup produk (Product Life Cycle) bihun tapioka padapenelitian ini dianalisis dengan metode Polli and Cook.Metode Polli and Cook adalah melihat perubahan persentase penjualan agroindustry dari tahun ke tahun dalam jangka waktu tertentu sepanjang produk mulai masuk ke dalam pasar saat penelitian.Hasil perhitungan dengan rumus Polli and Cook Agroindustri bihun tapioka dapat dilihat pada Tabel 2. 
Tabel 2. Hasil perhitungan dengan rumus Polii and Cook Agroindustri Bihun Tapioka

\begin{tabular}{ccccccc}
\hline \multirow{2}{*}{ Agroindustri Bihun Tapioka } & \multicolumn{4}{c}{ Perhitungan Polli and Cook } & \multirow{2}{*}{ Tahap } \\
\cline { 2 - 6 } & $\Delta \%(\mathrm{X})$ & $\mu$ & $\sigma$ & $\mathrm{Z}$ & $\mathrm{Y}$ & \\
\hline SJ & 13,36 & 3,34 & 9,75 & 8,21 & $(1,53)$ & Pertumbuhan \\
SH & 4,32 & 1,08 & 16,26 & 9,21 & $(7,05)$ & Kedewasaan \\
ML & 10,14 & 2,54 & 12,57 & 8,82 & $(3,75)$ & Pertumbuhan \\
BO & 14,79 & 3,70 & 23,96 & 15,68 & $(8,28)$ & Kedewasaan \\
MS & 32,61 & 8,15 & 23,42 & 19,86 & $(3,56)$ & Pertumbuhan \\
\hline
\end{tabular}

Keterangan :

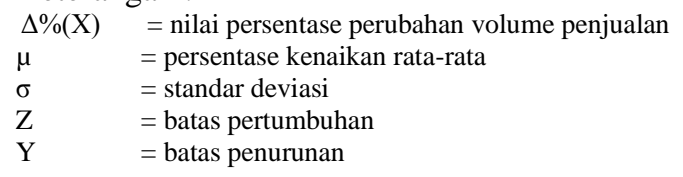

Hasil perhitungan dengan rumus Polli and Cook agroindustri bihun tapioka disajikan pada Tabel 2.Berdasarkan hasil penelitian diketahui bahwa Agroindustri SJ, Agroindustri ML, dan Agroindustri MS berada pada tahap pertumbuhan.Sedangkan Agroindustri SH dan Agroindustri BO berada pada posisi tahap kedewasaan pada daur hidup produk (Product Life Cycle).Diketahui bahwa volume penjualan kelima agroindustri bihun tapioka dalam 5 tahun terakhir mengalami naik turun (fluktuatif).

Penentuan tahapan daur hidup produk (Product Life Cycle) didasarkan pada nilai persentase volume penjualan dengan nilai batas untuk masing-masing tahapan. Hal ini dikarenakan bahan baku yang fluktuatif serta permintaan pasar yang tidak stabil. Apabila rata-rata penjualan suatu produk bihun tapioka (X) lebih kecil dari $0,5 \sigma$ maka produk tersebut dapat dikategorikan sebagai produk dalam tahap penurunan dan jika nilai X lebih besar daripada $0,5 \sigma$ dikategorikan produk bihun tapioka dalam posisi tahap pertumbuhan. Nilai $\mathrm{X}$ yang terletak antara rentang tersebut dikategorikan produk berada dalam posisi tahap kedewasaan.

Nilai batasan-batasan untuk menentukan posisi (tahap) produk menurut Polli and Cook sebagai berikut :

1) Batas penurunan (Decline) $=\Sigma \Delta \%(\mathrm{X})<\mathrm{Y}$

2) Batas pertumbuhan (Growth) $=\Sigma \Delta \%(\mathrm{X})>\mathrm{Z}$

3) Batas Kedewasaan (Mature) $=\mathrm{Y}<\Sigma \Delta \%(\mathrm{X})<\mathrm{Z}$ Diketahui nilai $Y$ diperoleh dari $\mu-0,5 \sigma$ dan nilai $\mathrm{Z}$ diperoleh dari $\mu+0,5 \sigma$. Penentuan posisi daur hidup produk pada masing-masing agroindustri diuraikan sebagai berikut :

\section{Agroindustri SJ}

Berdasarkan hasil perhitungan pada Tabel 2, diketahui bahwa jumlah nilai perubahan persentase penjualan adalah sebesar 13,36 $(X=13,36)$. Nilai batas pertumbuhan antara 8,21 dan nilai batas penurunan $-1,53$, sehingga nilai yang diperoleh pada jumlah persentase penjualan lebih besar dari nilai batas kedewasaan. Produk bihun tapioka Agroindustri SJ berada dalam tahap pertumbuhan dengan nilai batas sebagai berikut :

Tahap pertumbuhan (Growth) $=\mathrm{X}>\mu+0,5 \sigma=13,36>8,21$

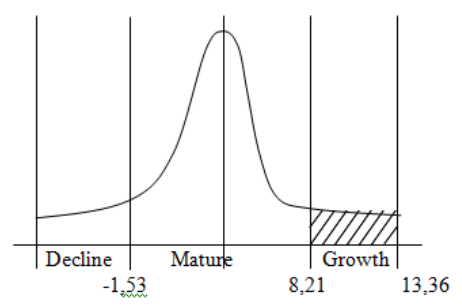

Gambar 1. Kurva PLC bihun tapioka Agroindustri SJ

\section{Agroindustri $\mathrm{SH}$}

Diketahui bahwa jumlah nilai perubahan persentase penjualan (dilihat pada Tabel 2) adalah sebesar 4,32 $(X=4,32)$. Nilai batas pertumbuhan antara 9,21 dan batas penurunan -7,05, sehingga nilai yang diperoleh berada diantara rentang batas pertumbuhan dan penurunan. Nilai jumlah persentase penjualan (X) lebih kecil daripada nilai batas pertumbuhan dan nilai jumlah persentase penjualan (X) lebih besar daripada nilai batas penurunan. Produk bihun tapioka Agroindustri SH berada dtahap kedewasaan dengan nilai batas sebagai berikut :

Tahap kedewasaan (Mature) $=$ $\mu-0,5 \sigma<X<\mu+0,5 \sigma=-7,05<X<9,21$

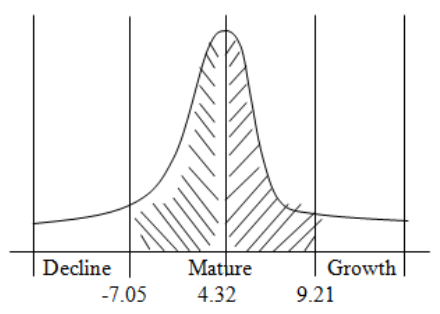

Gambar 2. Kurva PLC bihun tapioka Agroindustri SH 
3. Agroindustri ML

Diketahui bahwa jumlah nilai perubahan persentase penjualan adalah sebesar 10,14 $(X=10,14)$. Nilai batas pertumbuhan antara 8,82 dan nilai batas penurunan $-3,75$ dilihat pada Tabel 2 , sehingga jumlah persentase penjualan lebih besar dari nilai batas kedewasaan bihun tapioka Agroindustri ML berada di tahap pertumbuhan.

Tahap pertumbuhan (Growth) $=\mathrm{X}>\mu+0,5 \sigma=10,14>8,82$

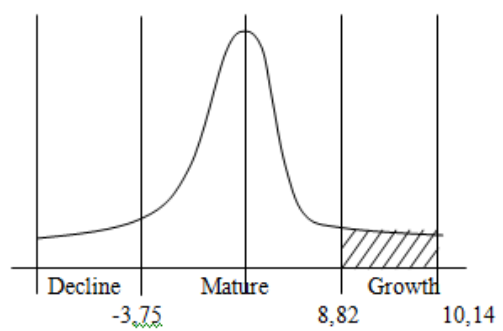

Gambar 3. Kurva PLC bihun tapioka Agroindustri ML

\section{Agroindustri BO}

Hasil perhitungan pada Tabel 2, nilai batas pertumbuhan antara 15,68 dan nilai batas penurunan $-8,28$, sehingga nilai yang diperoleh pada jumlah persentase penjualan berada diantara rentang batas pertumbuhan dan batas penurunan. Nilai jumlah persentase penjualan (X) lebih kecil daripada nilai batas pertumbuhan dan nilai jumlah persentase penjualan (X) lebih besar daripada nilai batas penurunan Produk bihun tapioka pada Agroindustri BO berada di tahap kedewasaan.
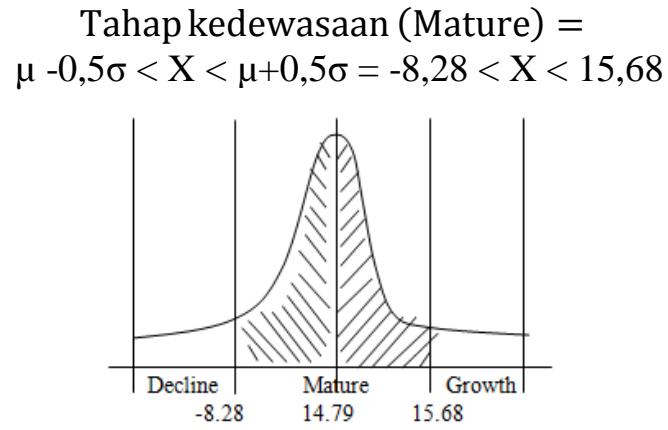

Gambar 4. Kurva PLC bihun tapioka Agroindustri BO

5. Agroindustri MS

Jumlah nilai perubahan persentase penjualan pada agroindustri adalah sebesar 32,61. Nilai batas pertumbuhan antara 19,86 dan nilai batas penurunan $-3,56$ dilihat pada Tabel 2, sehingga nilai yang diperoleh pada jumlah persentase penjualan lebih besar dari nilai batas kedewasaan. Produk bihun tapioka Agroindustri MS berada dalam tahap pertumbuhan.
Tahap pertumbuhan (Growth)

$=\mathrm{X}>$ ? $+0,5 \sigma=32,61>19,86$

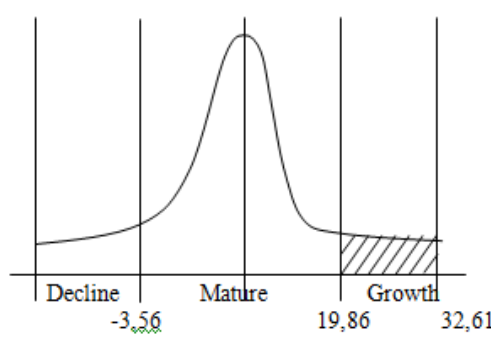

Gambar 5. Kurva PLC bihun tapioka Agroindustri MS

Agroindustri bihun tapioka yang berada pada tahap pertumbuhan lebih gencar memasarkan bihun tapioka dilihat dari jumlah distributor yang lebih banyak daripada Agroindustri yang berada di tahap kedewasaan. Jadi, agroindustri yang berada pada tahap pertumbuhan sebaiknya melakukan perluasan produk agar dapat mempertahankan penjualan dan agroindustri yang berada pada tahap kedewasaan sebaiknya mempertahankan strategi yang telah dilakukan dan memperluas wilayah pemasaran bihun tapioka.

\section{Persepsi Produsen terhadap Pengembangan Usaha Agroindustri Bihun Tapioka dan Keterkaitan Dengan Product Life Cycle}

Persepsi produsen terhadap pengembangan usaha merupakan pendapat masing-masing produsen tentang pengembangan usaha bihun tapioka. Persepsi produsen terhadap pengembangan usaha agroindustri bihun tapioka diukur melalui lima indikator skala likert. Diperoleh lima indikator yang digunakan untuk mengukur persepsi produsen terhadap pengembangan usaha agroindustri bihun tapioka.

Pentingnya pengembangan usaha agroindustri bihun tapioka termasuk dalam kategori "penting dilakukan" karena pengembangan usaha bihun tapioka dianggap penting oleh produsen bihun tapioka bagi kelangsungan usaha agroindustri bihun tapioka.Produsen ingin meningkatkan jumlah produk termasuk dalam kategori "ingin menambah" karena jumlah produk dikatakan baik jika produk tersebut tersedia secara terusmenerus. 
Tabel 3. Persepsi produsen terhadap pengembangan usaha agroindustri bihun tapioka dengan skala likert

\begin{tabular}{|c|c|c|}
\hline Indikator & Modus & Keterangan \\
\hline $\begin{array}{c}\text { Pentingnya } \\
\text { pengembangan usaha }\end{array}$ & 3 & $\begin{array}{c}\text { Penting } \\
\text { dilakukan }\end{array}$ \\
\hline Jumlah produk & 3 & $\begin{array}{c}\text { Ingin } \\
\text { menambah }\end{array}$ \\
\hline Pengembangan pasar & 2 & $\begin{array}{c}\text { Akan } \\
\text { melakukan }\end{array}$ \\
\hline Omzet usaha & 5 & Sangat tahu \\
\hline Kelangsungan usaha & 4 & Tahu \\
\hline Modus & 3 & Sedang \\
\hline
\end{tabular}

Pengembangan pasar menurut persepsi produsen termasuk dalam kategori "akan melakukan" namun belum ada peluang yang tepat. Produsen "sangat tahu" cara untuk menambah omzet dengan cara menjaga kualitas produk.

Pentingnya pengembangan usaha agroindustri bihun tapioka termasuk dalam kategori "penting dilakukan" karena pengembangan usaha bihun tapioka dianggap penting oleh produsen bihun tapioka bagi kelangsungan usaha agroindustri bihun tapioka.Produsen ingin meningkatkan jumlah produk termasuk dalam kategori "ingin menambah" karena jumlah produk dikatakan baik jika produk tersebut tersedia secara terusmenerus.Pengembangan pasar menurut persepsi produsen termasuk dalam kategori "akan melakukan" namun belum ada peluang yang tepat. Produsen "sangat tahu" cara untuk menambah omzet dengan cara menjaga kualitas produk.

Kelangsungan usaha menurut persepsi produsen termasuk ke dalam kategori "tahu" karena agroindustri bihun tapioka yang telah diteliti sudah berdiri sejak lama. Produsen mempertahankan kelangsungan usaha dengan cara menambah modal untuk produksi dan melakukan pembuatan atan pencatatan laporan keuangan secara periodik dan masih tradisional.

Secara keseluruhan, modus yang didapat dari lima indikator mengenai persepsi produsen adalah tiga yang termasuk ke dalam kategori "sedang". Hal ini berarti pengembangan usaha agroindustri bihun tapioka dianggap penting oleh produsen tetapi sulit untuk dilakukan. Hal tersebut dilihat dari tidak adanya perluasan daerah pemasaran, penambahan produk baru, serta tidak adanya kerjasama yang terjalin dengan pihak lain.
Tabel 4. Keterkaitan antara persepsi produsen dengan tahapan Product Life Cycle

\begin{tabular}{cccccc}
\hline \multirow{2}{*}{ Tahapan } & SJ & SH & ML & BO & MS \\
\cline { 2 - 6 } & \multicolumn{5}{c}{ Persepsi } \\
\hline Pertumbuhan & 3 & - & 3 & - & 4 \\
Kedewasaan & - & 4 & - & 3 & - \\
\hline
\end{tabular}

Hasil penelitian ini berbeda dengan hasil penelitian Lindaan, Rantung, dan Memah (2016) yang mendapatkan bahwa persepsi masyarakat dalam pengembangan industri rumah panggung dapat memberikan peningkatan ekonomi bagi masyarakat, karena ketersediaan bahan baku dan sumber daya manusia yang mendukung.

Keterkaitan persepsi produsen terhadap pengembangan usaha dengan Product Life Cycle dapat dilihat pada Tabel 4. Pada Tabel 4 tidak terlihat perbedaan dalam hal persepsi produsen terhadap pengembangan usaha, baik pada agroindustri yang berada pada tahap pertumbuhan maupun kedewasaan, sama-sama memiliki persepsi dengan nilai modus 3 dan 4.Nilai modus 3 menunjukkan bahwa produsen menganggap pengembangan usaha penting untuk dilakukan, namun harus membuat strategi pemasaran yang tepat agar dapat membuat konsumen membeli produk. Nilai modus 4 menunjukkan bahwa persepsi produsen mengenai kelangsungan usaha adalah tahu yang berarti pengembangan usaha dapat dilakukan dengan cara menambah modal untuk produksi.

\section{KESIMPULAN}

Posisi produk bihun tapioka dalam daur hidup produk (Product Life Cycle) pada Agroindustri Sinar Jaya, Agroindustri Monas Lancar, dan Agroindustri Moro Seneng berada pada Tahap Pertumbuhan, sedangkan Agroindustri Sinar Harapan dan Agroindustri Bintang Obor berada pada Tahap Kedewasaan. Pengembangan usaha dipersepsikan sebagai hal yang penting oleh produsen, namun sulit untuk dilakukan.Tidak ada keterkaitan antara persepsi produsen terhadap pengembangan usaha agroindustri dengan Product Life Cycle.

\section{DAFTAR PUSTAKA}

Almatsier S. 2001. Prinsip Dasar Ilmu Gizi. Gramedia Pustaka Utama. Jakarta.

Bazai FI, Sayekti WD, dan Lestari DAH. 2017. Penerapan strategi pemasaran dan aksesibilitas rumah tangga terhadap bihun 
tapioka di Kota Metro. JIIA, 5 (4): 399405. http://jurnal.fp.unila.ac.id/index.php/ JIA/article/view/1749/1552.[25 Oktober 2018].

BPS Provinsi Lampung. 2017. Lampung dalam Angka Tahun 2017.BPS Provinsi Lampung.Bandar Lampung.

Dinas Perindustrian Provinsi Lampung. 2017. Jumlah agroindustri ubi kayu di Provinsi Lampung. Bandar Lampung.

Kementerian Pertanian. 2016. Outlook Komoditas Petanian Tanaman Pangan..http://epublikasi.setjen.pertanian.g o.id/publikasi /outlook.[23 Oktober 2017].

Kotler P. 2000. Manajemen Pemasaran Edisi Milenium 1.PT Ikrar Mandiriabadi. Jakarta.

Lindaan MP, Rantung VV, dan Memah MY. 2016. Persepsi masyarakat terhadap pengembangan industri rumah panggung di Desa TombasianKecamatan Kawangkoan Barat Kabupaten Minahasa. Agri-Sosio Ekonomi Unstrat. 12(2A): 349-362. http://ejournal.unstrat.ac.id/index.php/ /jisep/article/view/12985.[20 Oktober 2017].
Maulani R, Dwiastuti R, dan Andriani DR. 2017. Analisis penetapan harga produk obat herbal olahan jamur dewa (Agaricus blazei Murril) pada CV. Asimas. Jurnal Ekonomi Pertanian dan Agribisnis (JEPA), 1 (2): 94107.https://jepa.ub.ac.id/index.php/jepa/arti cle/view/14. [23 Oktober 2017].

Sayekti WD, Prasmatiwi FE, dan Adawiyah R 2007. Kajian pemasaran bihun tapioka dalam rangka pengembangannya sebagai pangan alternatif.Prosiding Lokakarya Nasional Inovasi Teknologi Pertanian Mendukung Hari Pangan Sedunia 2007. Bandar Lampung, 25-26 Oktober 2007: 356368.http://kikp.pertanian.go.id/pustaka/opac /detail-opac?id=3685. [23 Oktober 2017].

Soekartawi. 2000. Pengantar Agroindustri. PT. Raja Grafindo Persada. Jakarta.

Vidyaningrum A, Sayekti WD, dan Adawiyah R. 2016. Referensi dan permintaan konsumen rumah tangga terhadap bihun tapioka di Kecamatan Purbolinggo Kabupaten Lampung Timur. JIIA, 4(2): 200-208. http://jurnal.fp.ac.id/index.php/JIA/article/ view/1238/1135. [20 Oktober 2017] . 